\title{
PREVALENCE OF SARCOCYSTS IN THE MUSCLES OF RAPTORS FROM A REHABILITATION CENTER IN NORTH CAROLINA
}

\author{
Alexa Rosypal von Dohlen ${ }^{1}$, David Scott ${ }^{2}$, J. P. Dubey ${ }^{3}$, and David S. Lindsay ${ }^{4}$ \\ ${ }^{1}$ Department of Natural Sciences and Mathematics, Johnson C. Smith University, Charlotte, North Carolina 28216. \\ ${ }^{2}$ Carolina Raptor Center, 6000 Sample Road, Huntersville, North Carolina 28078. \\ ${ }^{3}$ United States Department of Agriculture, Agricultural Research Service, Beltsville Agricultural Research Center, Animal Parasitic Diseases Laboratory, \\ Building 1001, Beltsville, Maryland 20705. \\ ${ }^{4}$ Department of Biomedical Sciences and Pathobiology, Virginia Maryland College of Veterinary Medicine, Center for One Health Research, Virginia Tech, \\ 1410 Prices Fork Road, Blacksburg, Virginia 24061. \\ Correspondence should be sent to David S. Lindsay at: lindsayd@vt.edu
}

\begin{tabular}{|c|c|}
\hline KEY WORDS & ABSTRACT \\
\hline
\end{tabular}

The life cycles of apicomplexan parasites in the genus Sarcocystis are heteroxenous (2-host), with carnivores usually being the definitive host and herbivores usually serving as intermediate hosts in predator-prey relationships. Raptors (birds of prey) are apex predators and are not consumed routinely by other carnivores. This makes the occurrence of sarcocysts in their muscles unusual (Crawley et al., 1982; Lindsay and Blagburn, 1999; Gjerde et al., 2018) from parasite transmission and food web perspectives. However, Sarcocystis spp. infection is common in the skeletal muscles of raptors from the southeastern United States (Lindsay and Blagburn, 1999). The prevalence of Sarco- cystis spp. sporocysts/oocysts in the feces of raptors from the Southeastern United States is also high $(>50 \%)$ (Lindsay and Blagburn, 1989; Lindsay et al., 1994; Yabsley et al., 2009). Little is known of the diversity of Sarcocystis spp. that use raptors either as intermediate or definitive hosts in North America. Sarcocystis spp. oocysts/sporocysts excreted in the feces of raptors, such as Sarcocystis calchasi in Accipiter species hawks in Europe (Olias et al., 2010, 2011), have the potential to be a source of fatal disease in avian species in the wild (Wünschmann et al., 2011; Olias et al., 2014; Hodo et al., 2016; Ziegler et al., 2018) and those housed in zoological exhibits (Rimoldi et al., 2013; Trupkiewicz et al., 2016). 
Table I. Species data on raptors from North and South Carolina, United States.

\begin{tabular}{|c|c|c|c|c|c|c|c|c|c|}
\hline \multirow[b]{2}{*}{ Species } & \multirow[b]{2}{*}{ Total } & \multirow[b]{2}{*}{ Males } & \multirow[b]{2}{*}{ Females } & \multirow[b]{2}{*}{ Unknown sex } & \multicolumn{5}{|c|}{ Age* } \\
\hline & & & & & $\mathrm{U}$ & $\mathrm{L}$ & HY & SY & ASY \\
\hline \multicolumn{10}{|l|}{ Order: Accipitriformes } \\
\hline \multicolumn{10}{|l|}{ Family: Accipitridae } \\
\hline Red-tailed hawk (Buteo jamaicensis) & $49 \dagger$ & 15 & 19 & 15 & 6 & 2 & 18 & 5 & 18 \\
\hline Red-shouldered hawk (Buteo lineatus) & $44 \dagger$ & 19 & 16 & 9 & 3 & 6 & 15 & 8 & 12 \\
\hline Broad-winged hawk (Buteo platypterus) & 6 & 0 & 4 & 2 & 3 & 1 & 2 & 0 & 0 \\
\hline Cooper's hawk (Accipiter cooperii) & $25 \dagger$ & 8 & 12 & 5 & 3 & 0 & 10 & 7 & 5 \\
\hline Sharp-shinned hawk (Accipiter striatus) & 1 & 1 & 0 & 0 & 0 & 0 & 0 & 1 & 0 \\
\hline Mississippi kite (Ictinia mississippiensis) & 1 & 0 & 1 & 0 & 0 & 0 & 0 & 0 & 1 \\
\hline \multicolumn{10}{|l|}{ Family: Cathartidae } \\
\hline Black vulture (Coragyps atratus) & 3 & 3 & 0 & 0 & 3 & 0 & 0 & 0 & 0 \\
\hline Turkey vulture (Cathartes aura) & 2 & 2 & 0 & 0 & 1 & 0 & 0 & 0 & 1 \\
\hline \multicolumn{10}{|l|}{ Family: Pandionidae } \\
\hline Osprey (Pandion haliaetus) & 5 & 1 & 2 & 2 & 1 & 0 & 2 & 2 & 1 \\
\hline \multicolumn{10}{|l|}{ Order: Falconiformes } \\
\hline \multicolumn{10}{|l|}{ Family: Falconidae } \\
\hline American kestrel (Falco sparverius) & 5 & 1 & 4 & 0 & 0 & 3 & 1 & 1 & 0 \\
\hline Merlin (Falco columbarius) & 1 & 1 & 0 & 0 & 0 & 0 & 0 & 0 & 1 \\
\hline \multicolumn{10}{|l|}{ Order: Strigiformes } \\
\hline \multicolumn{10}{|l|}{ Family: Strigidae } \\
\hline Barred owl (Strix varia) & $33 \dagger$ & 12 & 15 & 6 & 12 & 0 & 7 & 7 & 7 \\
\hline Great-horned owl (Bubo virginianus) & $21 \dagger$ & 7 & 9 & 5 & 8 & 0 & 4 & 3 & 6 \\
\hline Eastern screech owl (Megascops asio) & 3 & 1 & 1 & 1 & 2 & 0 & 0 & 0 & 1 \\
\hline \multicolumn{10}{|l|}{ Family: Tytonidae } \\
\hline Barn owl (Tyto alba) & 1 & 1 & 0 & 0 & 1 & 0 & 0 & 0 & 0 \\
\hline Unknown species & 4 & 0 & 0 & 4 & 4 & 0 & 0 & 0 & 0 \\
\hline Total & 204 & 72 & 83 & 49 & 47 & 12 & 58 & 34 & 53 \\
\hline
\end{tabular}

${ }^{*} \mathrm{U}=$ unknown age; $\mathrm{L}=$ local to the nest; $\mathrm{HY}=$ first year; $\mathrm{SY}=$ second year; $\mathrm{ASY}=$ after second year.

$\uparrow$ Group data statistically evaluated.

Sarcocystis encephalitis is being increasingly reported in raptors such as hawks, owls, and eagles in the United States (Aguilar et al., 1991; Dubey et al., 1991; Olson et al., 2007; Wünschmann et al., 2009, 2010). Sarcocystis falcatula, a parasite transmitted by Dipelphis spp. opossums and using several species of avian intermediate hosts in the Americas, has been implicated in cases of encephalitis in a great horned owl (Bubo virginianus) from Minnesota (Wünschmann et al., 2009) and eagles from Minnesota, Indiana, and Virginia (Wünschmann et al., 2010).

We conducted the present study from 2010 to 2018 to determine the prevalence of Sarcocystis spp. in the muscles of raptors to better understand the prevalence of infection related to disease in these apex predators. The long-term goal of our study is to unravel the life cycles of Sarcocystis spp. that use raptors as intermediate and definitive hosts in the Americas. This will help us determine the importance of raptors as victims of clinical Sarcocystis infection and as transmitters of disease to other vertebrates.

\section{MATERIALS AND METHODS}

\section{Source of raptor samples and history}

This study was approved by the Institutional Animal Care and Use Committee of Virginia Tech, Blacksburg, Virginia as a cadaver-only protocol. The samples used in this study were obtained from 204 patients from the Carolina Raptor Center (CRC) in Huntersville, North Carolina. All federal and local wildlife use permits were obtained and maintained by the CRC. The CRC is a conservation center for raptors from North and South Carolina and occasionally other southern states. The birds tested were either dead upon arrival, died in captivity, or were humanely euthanized because of poor prognosis and inability to be returned to their natural environments (Table I). The clinical history and necropsy findings, gender, approximate age, and species were recorded for most submissions and are archived at the CRC. Age was determined according to the methods of Pyle (1997). Raptor age was categorized as unknown, "local" for nestlings or hatchlings that are local to the nest, in "hatching year" for those that had left the nest but were in their first year, in "second year," and "after second year."

\section{Sample collection, processing, and examination}

A complete necropsy is routinely conducted on all birds that die or are euthanized at CRC, and samples of pectoral muscle and heart for the present study were obtained from raptors at necropsy by D.S. and fixed in $10 \%$ (v/v) neutral buffered formalin (NBF) solution or frozen at $-20 \mathrm{C}$. The NBF-fixed and frozen samples were collected from the CRC and transported to the Zoonotic Protozoal Diseases Laboratory (ZPDL), Center for One Health Research, Department of Biomedical Sciences and Pathobiology, Virginia-Maryland College of Veterinary Medicine, Virginia Tech, Blacksburg, Virginia, by A.v.D. Frozen muscle samples were thawed at room temperature and fixed in $10 \%$ NBF solution. All NBF-fixed samples were processed for 
Table II. Prevalence data on sarcocyst-positive raptors.

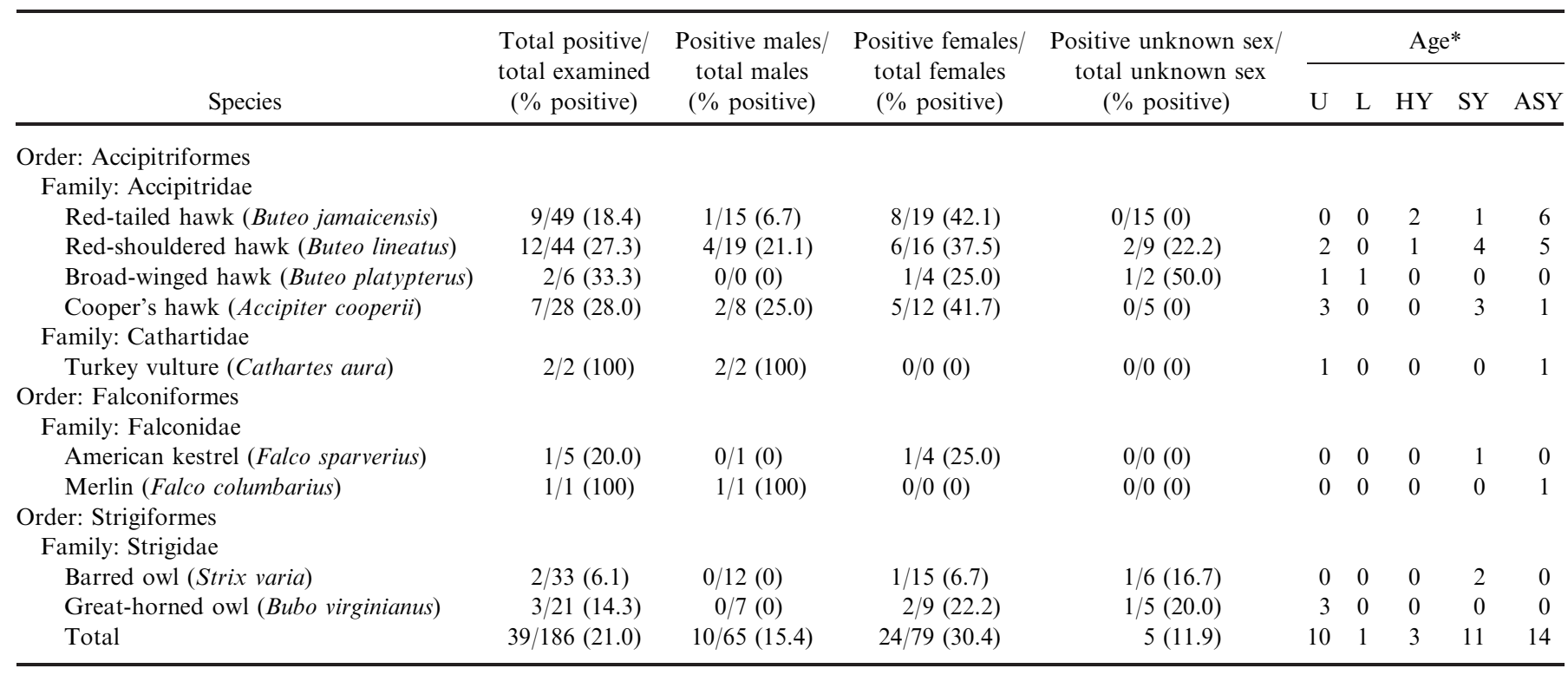

${ }^{*} \mathrm{U}=$ unknown age; $\mathrm{L}=$ local to the nest; $\mathrm{HY}=$ first year; $\mathrm{SY}=$ second year; $\mathrm{ASY}=$ after second year.

light microscopic examination and were stained with hematoxylin and eosin (H\&E). Slides were observed and photographed using an Olympus BH60 microscope (Olympus America Inc., Center Valley, Pennsylvania). The width of the sarcocyst wall was determined under oil immersion using a calibrated ocular micrometer. The H\&E slides were given an identification number and were examined by D.S.L., A.v.D., and J.P.D. with no knowledge of host species or clinical history. Necropsy records from sarcocyst positive raptors were reviewed to determine if neurological problems were recorded.

\section{Statistical analysis}

Statistical analysis was conducted by Dr. Stephen Werre of the Study Design and Statistics support service of the Virginia Maryland College of Veterinary Medicine, Virginia Tech. Data from raptor host species with 20 or more samples (red-tailed hawks [Buteo jamaicensis], red-shouldered hawks [Buteo lineatus], Cooper's hawks [Accipiter cooperii], barred owls [Strix varia], and great horned owls) were evaluated statistically. Data from raptors with less than 20 samples are presented (Tables I, II) but were not evaluated statistically because of the few numbers of samples examined. Bivariable associations between prevalence of sarcocysts and risk factors (sex and age) were assessed using Fisher's exact test using SAS version 9.4 (Cary, North Carolina). Statistical significance was set to $P<0.05$.

\section{RESULTS}

Samples were obtained from 204 raptors; none were eagles (Tables I, II). Most $(\mathrm{n}=200)$ were from 3 Orders and 6 Families compromising 15 host species while the identities of 4 raptors were not reported. Hawks of the Order Accipitriformes and its Families Accipitridae $(\mathrm{n}=126)$, Cathartidae $(\mathrm{n}=5)$, and Pandionidae $(\mathrm{n}=5)$ accounted for 136 samples. Falcons of the Order Falconiformes and the Family Falconidae accounted for 6 samples. Owls of the Order Strigiformes and the Families
Tytonidae $(\mathrm{n}=1)$ and Strigidae $(\mathrm{n}=57)$ accounted for 58 samples. The numbers of raptors of each host species examined are presented in Table I. The gender was recorded on 115 of the 204 raptors and 72 were male and 83 were female (Table I).

Sarcocysts were seen in tissue sections of muscle from 39 $(19.1 \%)$ of 204 raptors (Fig. 1). Sarcocysts were observed in pectoral muscles from 39 and in heart muscles from 9 raptors. The 9 sarcocysts-positive heart samples also had sarcocysts in their pectoral muscles. Few sarcocysts (3-5) were usually present in the muscle or heart samples examined. Structurally, sarcocysts were classified into 2 different groups based on sarcocyst wall thickness in 37 raptors. Thin-walled sarcocysts with walls that were $\leq 1 \mu \mathrm{m}$ were observed in $23(62 \%)$ (Fig. 1A) and 14 (38\%) had sarcocysts with walls that were $2-4 \mu \mathrm{m}$ thick (Fig. 1B, C). No attempt was made to separate the sarcocysts other than thin- or thick-walled because orientation of sarcocysts in sections was not always optimal to determine additional structural features. The number of raptors with both types of sarcocysts was not determined. The projections on thick-walled sarcocysts were uniform or were occasionally present as irregular, spike-like projections. The irregular, spike-like projections could be present on 1 area of a sarcocyst while uniform projections would be present on other regions.

The number of sarcocyst-positive raptors increased as the raptors aged (Table I). One broad-winged hawk (Buteo platypterus) was an orphaned nestling that was "local" to the nest and 2 red-tailed hawks and a red-shouldered hawk were recorded as in the hatching year (first year). The recorded age of all other sarcocyst positive raptors was $2 \mathrm{yr}$ or greater (Table I). Association between prevalence of sarcocysts and age was significant for red-shouldered hawks $(P=0.022)$ and Cooper's hawks $(P=0.028)$ (Table $\mathrm{I})$.

Prevalence based on raptor gender is provided in Table II. The prevalence of sarcocysts in male red-tailed hawks (1 of $15 ; 6.7 \%$ ), red-shouldered hawks (4 of $19 ; 21.1 \%$ ), and Cooper's hawks ( 2 of $8 ; 25 \%$ ) was less than the values in female red-tailed hawks ( 8 of 

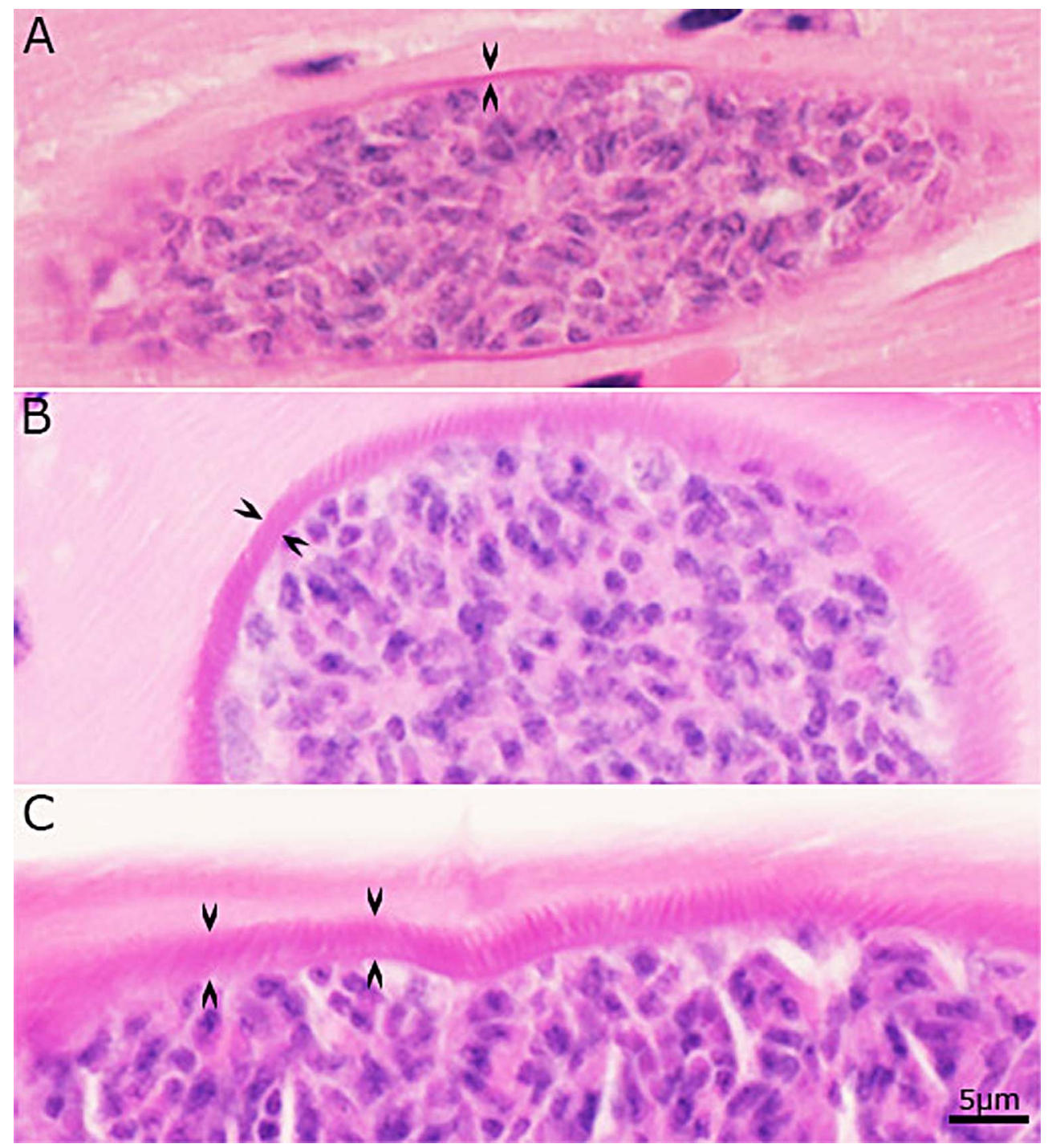

Figure 1. Histological tissue sections of pectoral muscle from raptors demonstrating thin- and thick-walled sarcocysts. H\&E. (A) Section from a male merlin (Falco columbarius) demonstrating a sarcocyst with a thin wall (arrowheads). (B) Tissue section from a female red-tailed hawk (Buteo jamaicensis) demonstrating a sarcocyst with a thick wall (arrowheads). (C) Section of a sarcocyst from same histological sample as 1B. Note the thick wall (arrowheads) and how the appearance of the wall varies along its length. Color version available online.

$19 ; 42.1 \%$ ), red-shouldered hawks (6 of $16 ; 37.5 \%$ ), and Cooper's hawks (5 of $12 ; 41.7 \%$ ). No sarcocysts were observed in male barred owls ( 0 of 12) or great horned owls (0 of 7) while female barred owls ( 1 of 15) and great horned owls ( 2 of 9) had a prevalence of $6.7 \%$ and $22.2 \%$, respectively (Table II). The association between presence of sarcocysts and gender was significant only for red-tailed hawks $(P=0.047)$ (Table II).

A review of the 39 case records was inconclusive because the history of most birds did not include information on their behavior prior to being found by the donors that had submitted them to the CRC or because submission was due to circumstances that could have induced neurological trauma. Four had neurological signs that were not associated with obvious trauma, but histological examination of central nervous system tissue was not conducted making inferences to Sarcocystis spp. or other parasitic pathogens impossible.

\section{DISCUSSION}

Cases of Sarcocystis encephalitis in raptors have been increasingly reported in North America after the first 2 cases of Sarcocystis-associated encephalitis were reported in 1991 in a golden eagle (Aquila chrysaetos) from Virginia (Dubey et al., 1991) and an immature northern goshawk (Accipiter gentiles atricapillus) from Minnesota (Aguilar et al., 1991). Sarcocysts were not reported in the hearts of these raptors; no other muscle was examined histologically. A case of Sarcocystis encephalitis was reported in a bald eagle from Missouri (Olsen et al., 2007). Two types of sarcocysts, thin and thick, were reported in muscles of the bald eagle (Olsen et al., 2007). Sarcocystis spp. encephalitis in raptors presents with various clinical signs including head tilt, deficits in the limbs, poor grasp reflex, and other neurological signs (Wünschmann et al., 2009, 2010). Sarcocystis falcatula was identified using immunohistochemical methods and PCR in the 
CNS of a free-ranging great horned owl from southern Minnesota that had severe neurological signs and was unable to fly prior to euthanasia and necropsy (Wünschmann et al., 2009). Sarcocysts were not observed in muscle of the great horned owl. Three bald eagles and 1 golden eagle from 3 states (Minnesota, Indiana, and Virginia) were admitted to rehabilitation facilities with emaciation, lethargy, and an inability to fly. A bald eagle and the golden eagle were diagnosed with Sarcocystis spp. encephalitis (Wünschmann et al., 2010) and the remaining 2 bald eagles had Sarcocystis schizonts in their lungs. Sarcocysts were present in the muscles or hearts of the 4 eagles. PCR and immunohistochemical staining indicated that $S$. falcatula or S. falcatula-like organisms were present in the golden eagle and in 2 of the 3 bald eagles. The identity of the Sarcocystis spp. in the bald eagle with encephalitis could not be determined using the PCR method employed on formalin-fixed tissue (Wünschmann et al., 2010). Raptors potentially can be exposed to $S$. falcatula oocysts/sporocysts on the surface of their prey and inadvertently consume the parasite while ingesting prey or by ingesting oocysts/sporocysts in water. They also may ingest $S$. falcatula oocysts/sporocysts while ingesting the intestines of Didelphis species opossums with patent infections.

Some of the thin-walled sarcocysts may be $S$. calchasi because they are consistent with the original description of the sarcocyst wall (Olias et al., 2010) of S. calchasi. The report indicates the sarcocyst wall is smooth and without protrusions. None of the species of sarcocyst found in muscle of raptors have been named (Dubey et al., 2016). The sarcocysts are few in number, making it difficult to determine their ultrastructure and provide details of structural features.

We used histology in the present study to evaluate Sarcocystis prevalence. It has the advantage in providing structural data on the sarcocyst which can be used in species identification and also that frozen tissue can be thawed and processed for H\&E staining with little to no loss of architecture (Dubey et al., 2016). However, histological methods usually underestimate the prevalence of infection because only a small portion of muscle can be examined using this method (Dubey et al., 2016). The use of a muscle digestion method will detect more positive samples, but the identity of the Sarcocystis spp. cannot be determined based on the structure of bradyzoites present in digested samples (Dubey et al., 2016). Our findings of $39(19.1 \%)$ of 204 raptors is less than the 28 $(37.8 \%)$ of the 74 cases reported in a study from a raptor center in Alabama (Lindsay and Blagburn, 1999) using histology to detect sarcocysts. These authors also used a muscle digestion technique and found that Sarcocystis-like bradyzoites were in digests of 52 $(45.6 \%)$ of 114 samples (Lindsay and Blagburn, 1999). PCR is a powerful technique but it is also based on a very small sample (50 $\mathrm{mg}$ ) of tissue. In the course of this study, we attempted to use internal transcribed spacer (ITS) PCR to detect Sarcocystis infections ( $\mathrm{Li}$ et al., 2002) using 50-mg samples from frozen muscle once $H \& E$ results were determined. We found that histologically positive birds would often be ITS PCR-negative and that some histologically negative samples would be ITS PCRpositive (D.S.L., unpubl. data). Based on these observations, we did not elect to use PCR in the present study to estimate prevalence or in attempts to determine Sarcocystis spp. (Tanhauser et al., 1999; Olias et al., 2011).

Thin-walled sarcocysts were found in a male merlin (Falco columbarius) (Fig. 1A; (Table II). All other species of Sarcocystis muscle-positive raptors observed in the present study (Table II) have previously been documented (Lindsay and Blagburn, 1999). We did not observe sarcocysts in a sharp-shinned hawk (Accipiter striatus), Mississippi kite (Ictinia mississippiensis), and 3 black vultures (Coragyps atratus); however, Lindsay and Blagburn (1999) found sarcocysts in these raptors in their study. Neither Lindsay and Blagburn (1999) nor the present study found sarcocysts in ospreys (Pandion haliaetus) or barn owls (Tyto alba).

The age of most sarcocyst-positive raptors (Table II) indicates that raptors do not appear to acquire muscle infection with sarcocysts until they leave the nest. This suggests a lack of exposure to sporocysts until after they have matured enough to leave the nest and begin to become exposed to sporocysts in the environment.

We found evidence that female red-tailed hawks were more likely to become infected with a Sarcocystis spp. that develops in their muscles than were males. Basic differences in physiological, hormonal, and immunological parameters between females and males of the same host species may explain our findings, but additional research is needed to support the significant difference $(P<0.047)$ in gender we observed. These include increasing the number of samples examined and looking for other potential explanations of why gender would influence the exposure to infective stages that are found in the environment.

\section{ACKNOWLEDGMENTS}

We would like to thank the staff and students at the Carolina Raptor Center in Huntersville, North Carolina for providing us with samples. This work was supported by grant 1505407 from the National Science Foundation Historically Black Colleges and Universities Undergraduate Program to A.v.D. and an Intramural Research Competition (IRC) grant from the VirginiaMaryland College of Veterinary Medicine to D.S.L. We thank the numerous undergraduate students from Johnson C. Smith University and undergraduate and graduate students from Virginia Tech for assistance with this project. Mention of trade names or commercial products in this publication is solely for the purpose of providing specific information and does not imply recommendation or endorsement by the U.S. Department of Agriculture; USDA is an equal opportunity provider and employer.

\section{CONFLICTS OF INTEREST}

The authors declare no conflicts of interest.

\section{LITERATURE CITED}

Aguilar, R. F., D. P. Shaw, J. P. Dubey, and P. Redig. 1991. Sarcocystis-associated encephalitis in an immature northern goshawk (Accipiter gentilis atricapillus). Journal of Zoo and Wildlife Medicine 22: 466-469.

Crawley, R. R., J. V. Ernst, and J. L. Milton. 1982. Sarcocystis in a bald eagle (Haliaeetus leucocephalus). Journal of Wildlife Diseases 18: 253-255.

Dubey, J. P., R. Calero-Bernal, B. M. Rosenthal, C. A. Speer, AND R. FAYer. 2016. Sarcocystosis of animals and humans, 2nd ed. CRC Press, Taylor and Francis Group, Boca Raton, Florida, 481 p. 
Dubey, J. P., S. L. Porter, A. L. Hattel, D. C. Kradel, M. J. TOPPER, AND L. JohnSON. 1991. Sarcocystis-associated clinical encephalitis in a golden eagle (Aquila chrysaetos). Journal of Zoo and Wildlife Medicine 22: 233-236.

Gjerde, B., T. Vikøren, And. I. S. Hamnes. 2018. Molecular identification of Sarcocystis halieti n. sp., Sarcocystis lari and Sarcocystis truncata in the intestine of a white-tailed sea eagle (Haliaeetus albicilla) in Norway. International Journal for Parasitology: Parasites and Wildlife 7: 1-11.

Hodo, C. L., D. B. Whitley, S. A. Hamer, W. V. Corapi, K. Snowden, J. J. Heatley, and A. R. Hoffmann. 2016. Histopathologic and molecular characterization of Sarcocystis calchasi encephalitis in white-winged doves (Zenaida asiatica) and Eurasian collared doves (Streptopelia decaocto), East-central Texas, USA, 2010-13. Journal of Wildlife Diseases 52: 395-399.

Li, Q. Q., Z. Q. Yang, Y. X. Zuo, S. W. Attwood, X. W. Chen, AND Y. P. Zhang. 2002. A PCR-based RFLP analysis of Sarcocystis cruzi (Protozoa: Sarcocystidae) in Yunnan Province, PR China, reveals the water buffalo (Bubalus bubalis) as a natural intermediate host. Journal of Parasitology 88: 1259-1261.

LindSAY, D. S., AND B. L. BlagBURn. 1989. Caryospora uptoni and Frenkelia sp.-like coccidial infections in red-tailed hawks (Buteo borealis). Journal of Wildlife Diseases 25: 407-409.

Lindsay, D. S., AND B. L. Blagburn. 1999. Prevalence of encysted apicomplexans in muscles of raptors. Veterinary Parasitology 80: 341-344.

Lindsay, D. S., B. L. Blagburn, S. J. Upton, C. A. Sundermann, R. D. McKnown, and B. L. Blagburn. 1994. Caryospora tremula and Sarcocystis sp. from turkey vultures, Cathartes aura: Redescriptions and attempted transmission to rodents. Journal of the Helminthological Society of Washington 61: $12-16$.

Olias, P., A. D. Gruber, H. M. Hafez, A. O. Heydorn, H. Mehlhorn, And M. Lierz. 2010. Sarcocystis calchasi sp. nov. of the domestic pigeon (Columba livia f. domestica) and the Northern goshawk (Accipiter gentilis): Light and electron microscopical characteristics. Parasitology Research 106: 577-585.

Olias, P., A. D. Gruber, L. Olias, J. Krucken, M. Lierz, and A. D. Gruber. 2011. High prevalence of Sarcocystis calchasi sporocysts in European Accipiter hawks. Veterinary Parasitology 175: 230-236.

Olias, P., K. Maier, A. Wünschmann, L. Reed, A. G. Armien, D. P. Shaw, A. D. Gruber, And M. Lierz. 2014. Sarcocystis calchasi has an expanded host range and induces neurological disease in cockatiels (Nymphicus hollandicus) and North
American rock pigeons (Columbia livia f. dom.). Veterinary Parasitology 200: 59-65.

Olson, E. J., A. Wünschmann, And J. P. Dubey. 2007. Sarcocystis sp.-associated meningoencephalitis in a bald eagle (Haliaeetus leucocephalus). Journal of Veterinary Diagnostic Investigation 19: 564-568.

Pyle, P. 1997. Identification guide to North American birds. Parts 1 and 2. Slate Creek Press, Point Reyes Station, California, $732 \mathrm{p}$.

Rimoldi, G., B. Speer, J. F. Wellehan, D. S. Bradway, L. Wright, D. Reavill, B. C. Barr, A. Childress, H. L. Shivaprasad, AND R. P. Chin. 2013. An outbreak of Sarcocystis calchasi encephalitis in multiple psittacine species within an enclosed zoological aviary. Journal of Veterinary Diagnostic Investigation 25: 775-781.

Tanhauser, S. M., C. A. Yowell, T. J. Cutler, E. C. Greiner, R. J. MacKay, And J. B. Dame. 1999. Multiple DNA markers differentiate Sarcocystis neurona and Sarcocystis falcatula. Journal of Parasitology 85: 221-228.

Trupkiewicz, J. G., R. Calero-Bernal, S. K. Verma, J. Mowery, S. Davidson, P. Habecker, T. A. Georoff, D. M. Laleggio, AND J. P. Dubey. 2016. Acute, fatal Sarcocystis calchasiassociated hepatitis in roller pigeons (Columba livia f. dom.) at Philadelphia Zoo. Veterinary Parasitology 216: 52-58.

Wünschmann, A., A. G. Armien, L. Reed, A. D. Gruber, and P. Olias. 2011. Sarcocystis calchasi-associated neurologic disease in a domestic pigeon in North America. Transboundary and Emerging Diseases 58: 526-530.

Wünschmann, A., D. Rejmanek, P. A. Conrad, N. Hall, L. Cruz-Martinez, S. B. Vaughn, and B. C. Barr. 2010. Natural fatal Sarcocystis falcatula infections in free-ranging eagles in North America. Journal of Veterinary Diagnostic Investigation 22: 282-289.

Wünschmann, A., D. Rejmanek, L. Cruz-Martinez, and B. C. BARr. 2009. Sarcocystis falcatula-associated encephalitis in a free-ranging great horned owl (Bubo virginianus). Journal of Veterinary Diagnostic Investigation 21: 283-287.

Yabsley, M. J., A. E. Ellis, D. E. Stallknecht, and E. W. Howerth. 2009. Characterization of Sarcocystis from four species of hawks from Georgia, USA. Journal of Parasitology 95: 256-259.

Ziegler, L., S. L. Parmentier, D. Fischer, J. Heckmann, R. Klopfleisch, O. Kershaw, U. Ziegler, H. Neurath, V. SCHMidT, AND M. Lierz. 2018. Investigations into causes of neurologic signs and mortality and the first identification of Sarcocystis calchasi in free-ranging woodpeckers in Germany. Journal of Zoo and Wildlife Medicine 49: 247-251. 